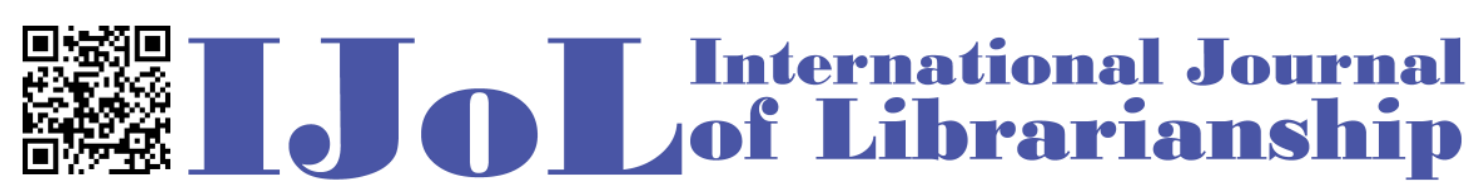

ISSN: 2474-3542 Journal homepage: http://journal.calaijol.org

\title{
Challenges that Affect the Utilization of KLISC's Resources and Services at University of Nairobi
}

\author{
Naomy Waithera Mwaurah and Ben Wekalao Namande
}

\section{Abstract:}

It is not feasible for a library to hold or acquire a full collection of information resources which may be required by its patrons. To deal with this issue, library cooperation was adopted, for instance, interlibrary loaning, document delivery and library network, formed to build the acquiring capacity of cooperating institutions to grow the accessibility of information resources and offer computerized services. In Kenya, there is KLISC which has carried out commendable activities to support research in Kenya. KLISC has done admirable exercises to support research in Kenya. These exercises incorporate collaborative acquisition of information resources, ICT training of information experts and the preparation of researchers to improve their abilities in retrieving information. Despite the activities and services that KLISC provide, its resources are yet to be appreciated by a majority of the users of the member institutions. Also, not all information providers and institutions of higher learning are members. Kenya has over 600 institutions but only 112 are KLISC members as of 2018 and the numbers keep reducing. The study therefore tried to identify the challenges that the KLISC members face that could be affecting utilization of the electronic resources, members pulling out and also discouraging other institutions from joining. The study found out that KLISC members experienced the following challenges; slow internet connectivity, information illiteracy, lack of searching skills, low awareness levels, slow downloading speed, unfriendly platforms, password requirements for some databases, poor ICT infrastructure, poor ICT skills for both users and staff, delays in releasing of funds by the management, and slow communication from the publishers. KLISC itself faces the following challenges: members do not efficiently communicate about their information needs, lack of sponsorship since INASP pulled out, delay by KLISC's members to pay their annual subscription fee, and the management team is overwhelmed by work. The study therefore recommended the following: Institutions should invest more on ICT infrastructure, KLISC should come up with a way of ensuring relevancy, KLISC should stand on its own as an institution and acquire its own offices and employ staff who will just be working for KLISC, KLISC should create a mini-consortium to cater for research institutions and also other specialized fields in different institutions in Kenya, KLISC should come up with a way of dealing with individual defaulters in a way that does not affect the other members, the publishers should improve the interfaces of their 
databases to make them user friendly and easy to navigate, and the publishers should also ensure fast communications with the institutions.

To cite this article:

Mwaurah, N.W., \& Namande, B. W. (2021). Challenges that affect the utilization of KLISC's resources and services at University of Nairobi. International Journal of Librarianship, 6(1), 27-36. https://doi.org/10.23974/ijol.2021.vol6.1.128

To submit your article to this journal:

Go to https://ojs.calaijol.org/index.php/ijol/about/submissions 


\title{
Challenges that Affect the Utilization of KLISC's Resources and Services at University of Nairobi
}

\author{
Naomy Waithera Mwaurah, Boma International Hospitality College, Kenya \\ Ben Wekalao Namande, Kisii University, Kenya
}

\begin{abstract}
It is not feasible for a library to hold or acquire a full collection of information resources which may be required by its patrons. To deal with this issue, library cooperation was adopted, for instance, interlibrary loaning, document delivery and library network, formed to build the acquiring capacity of cooperating institutions to grow the accessibility of information resources and offer computerized services. In Kenya, there is KLISC which has carried out commendable activities to support research in Kenya. KLISC has done admirable exercises to support research in Kenya. These exercises incorporate collaborative acquisition of information resources, ICT training of information experts and the preparation of researchers to improve their abilities in retrieving information. Despite the activities and services that KLISC provide, its resources are yet to be appreciated by a majority of the users of the member institutions. Also, not all information providers and institutions of higher learning are members. Kenya has over 600 institutions but only 112 are KLISC members as of 2018 and the numbers keep reducing. The study therefore tried to identify the challenges that the KLISC members face that could be affecting utilization of the electronic resources, members pulling out and also discouraging other institutions from joining. The study found out that KLISC members experienced the following challenges; slow internet connectivity, information illiteracy, lack of searching skills, low awareness levels, slow downloading speed, unfriendly platforms, password requirements for some databases, poor ICT infrastructure, poor ICT skills for both users and staff, delays in releasing of funds by the management, and slow communication from the publishers. KLISC itself faces the following challenges: members do not efficiently communicate about their information needs, lack of sponsorship since INASP pulled out, delay by KLISC's members to pay their annual subscription fee, and the management team is overwhelmed by work. The study therefore recommended the following: Institutions should invest more on ICT infrastructure, KLISC should come up with a way of ensuring relevancy, KLISC should stand on its own as an institution and acquire its own offices and employ staff who will just be working for KLISC, KLISC should create a mini-consortium to cater for research institutions and also other specialized fields in different institutions in Kenya, KLISC should come up with a way of dealing with individual defaulters in a way that does not affect the other members, the publishers should improve the interfaces of their databases to make them user friendly and easy to navigate, and the publishers should also ensure fast communications with the institutions.
\end{abstract}


Keywords: Information Resources, Library Consortium, Challenges, Kenya Library and Information Service Consortium (KLISC), University of Nairobi

\section{BACKGROUND OF THE STUDY}

It is not feasible for a library to hold or acquire full collection of information resources which may be required by its patrons. To deal with this issue, library collaboration began long ago, for example, interlibrary loaning, document delivery and library network. Today, the more traditional arrangement of resource sharing is referred to library consortia. Consortium refers to, "co-operation, co-ordination and collaboration between and amongst libraries for the purpose of sharing information resources." Through this collaboration, it has become possible to acquire information resources in stabilized and cheaper prices (Islam \& Melezbah-ul-Islam, 2000). Consortia are formed to build the acquiring capacity of cooperating institutions to grow the accessibility of information resources and offer computerized services. Consortia may be formed at different levels such as: local, regional, national or international level, on a functional or formal basis, or on subject basis (Chander \&Gupta, 2015).

In the United States, Academic library consortia have been in existence for many decades, after gaining force in the 1970s courtesy of shared catalogues and then later in the 1990s transitioning into the shared acquisition of e-resources (Chadwell, 2011).

In India, the Ministry of Human Resource Development (MHRD) has formed the Indian National Digital Library in Science and Technology (INDEST) Consortium. It is through this consortium that the ministry contributes funds needed for the subscription to electronic information resources for 38 major institutions, and other centrally funded government institutions. In addition, 60 government-aided engineering college and technical departments in universities have furthermore joined the consortium with the monetary support from the Indian Council for Technical Education. Institutions in the INDEST consortium have an arranged foundation of PCs accessible at their institutions (Galyani \& Talawar, 2009).

In Nigeria, various categories of library collaborations exist such as: the National Virtual Library project; Nigerian University Network; and Nigerian University Libraries Consortium. They were created to accommodate all academic institutions with an aim of increasing scholarly and research information centres in Nigeria. Courtesy of ICTs advancements, there has been a move that has prompted libraries shifting from holding specific physical information resources locally to offering access to various information resources, irrespective of format and location. This move from proprietorship to access seems to be the power that progresses consortia development amongst libraries and moreover extending the quantity of researches on library collaborations in Nigeria. These realities are obvious in the continuous library trainings, courses and meetings sorted out by the Nigerian Library Association (NLA) and Librarian Registration Council of Nigeria with prominence on open access for library and information centres, and information sharing, libraries and citizens as cohorts in managing the information society (Posigha, Godfrey, \& Seimode, 2015).

The University of Nairobi is located in Nairobi City which has a population of over 3.5 million. Nairobi has an area of over 700 square kilometres and stands at an altitude of 1,675 meters above sea level. Nairobi is the capital, commercial, administrative and cultural centre of Kenya. The Library Department is a member and has been the host of KLISC until 2019 when 
Kenyatta University took over. Through this joint effort, the Library has taken part in various preparing workshops to upgrade staff capacity as well as enhance membership. The school of Business was initiated in the academic year 1956/57. It has three departments, namely: Business Administration, Finance and Accounting and Management Science. It offers 6 post-graduate courses, that is, Master of Business Administration, Master of Science in Finance, Master of Science in Marketing, Master of Science in Human Resource Management, Master of Science in Entrepreneurship and Innovations management, and Doctor of Philosophy in Business Administration. It has over 13,000 students with two satellite campuses in Mombasa and Kisumu (University of Nairobi, 2017).

\section{Challenges faced by Consortia Members in Accessing and Using the Information Resources}

Although a library collaboration fulfils various requirements that might be hard to accomplish when sought after independently, it equally brings concerns and difficulties that libraries rarely experience as sole elements. As reported in the Philippines, many library consortia members differ in various aspects such as collection range, facilities, source of money, technical development, organization, and category of patrons served. The differences may make it difficult for the member libraries to agree on some aspects (Fresnido \& Yap, 2014). They report that the different level of technological advancement is the most common in the Philippines. This becomes a problem when some members have less to provide in terms of electronic resources and ICT infrastructures as well as digital and online services. These members are forced to depend on the institutions that have and this in a way misshapes the idea of collaboration and correspondence and replaces such with reliance. This wrecks the feeling of parity as far as resource sharing is concerned.

The survey by Veenapani, Singh and Devi in 2008, "To Determine the Use of UGCInfonet Digital Library Consortium by Teachers and Researchers," identified the challenges experienced by the clients of the Consortium as: ICT illiteracy, inconsistent power supply, poor web availability, inadequate PCs and issues in selection of required journal titles (Veenapani, Singh, \& Devi, 2008). Another study done on "UGC-Infornet Digital Library Consortium to Access Its Awareness and Usage among Faculty Members of State Universities in Tamil Nadu," found the following challenges: insufficient internet points in University library, user-unfriendly e-journal platforms, slow internet bandwidth, technical problems, frequent power cut, lack of important information sources, lack of support from library staff (Thanuskodi, 2012).

Dzandza and Alemna (2011) reported that it was only South Africa from the whole of Africa which has made serious endeavours in the advancement of consortia. By the time, South Africa had five university library consortia, namely: CALICO (CApe Library COoperative), ESAL (Eastern Seaboard Association of Libraries), FRELICO (FREe State Libraries and Information COnsortium), GAELI (Gauteng and Environs Library Consortium), and SEALS (South Eastern Academic Libraries' System). However, the inspiration and the nature, power, and achievement of collaboration vary broadly among the five named library consortia in South Africa. They face a number of varying challenges ranging from socio-political and language barriers to telecommunication infrastructure.

In Ghana, it was not until 2004 when the Consortium of Academic and Research Libraries in Ghana (CARLIGH) was created as the single library consortium with only 18 members as of 2009. CARLIGH aims to gather libraries from scholarly and research institutions 
cooperatively to aide in binding resources to realize a common goal of providing sufficient information to their patrons (Dzandza\&Alemna, 2011). Dzanda and Alemna (2011) reported the following challenges as being faced by CARLIGH members:

- Internet breakdown

- Challenges dealing with the publishers

- Much more learning needed by the staff

- Complexity in accessing some of the databases

- Denied access to full texts from some databases

- Lengthy and difficult subscription procedures

- Delayed release of finances from mother institution

- Irrelevant electronic resources

- Escalating prices of electronic resources

- Disagreement among members

Galyani and Talawar (2009) recognize financing issues as a fundamental test. Joining a consortium calls for beginning interests in licenses and ICT. Libraries are additionally much of the time not prepared to trade out the investment funds offered by not taking care of the print version of the journals. Various libraries are in this way hesitant to join consortia understandings particularly where publishers constrain instalments for off-consortia conveyance of documents, either in electronic or paper format. There is likewise the test of ventures to be made in local, consortium based, focal hardware set up, mounting of information, progression of interfaces, organization of access among others. Academic libraries likewise encounter difficulties, for example, expanding requests and elevated standards from clients, spending cuts, elevated prices of library materials particularly electronic journals, and increase in the quantity of information resources at large.

Chauhan and Mahajan (2013) indicated that many universities in India are unable to sustain subscriptions to even core journals because of the ever escalating prices of journal subscriptions. However, numerous measures have been put in place to overcome the price increase of scholarly literature, information surplus and rising information needs of users.

According to a survey done by Kiilu, Gathoni and Kabugu (2011) on "Monitoring and evaluation of electronic resources in academic and research institutions in Kenya," the following challenges were reported to be hindering effective access to electronic information resources: poor searching skills, unstable and unreliable internet connectivity, lack of access to computers, not aware of any training on e-resources, not aware of any e-resources, unfriendly platforms.

The survey concluded that more work was required to adequately promote the available resources. Provision and utilization of e-resources entails the use of ICT facilities which includes steady and consistent internet connectivity and computer terminals. The survey therefore concluded that improved infrastructure would enhance access to and use of e-resources (Kiilu, Gathoni, \& Kabugu, 2011). 
Mwanzia (2014) cites the following challenges faced by KLISC members: Poor ICT infrastructure, slow internet speed, password requirements for some publishers, slow communication by publishers, some publishers do not allow access to full text, long embargo periods, lack of searching skills, use of IP that restrict use within institutions, high subscription fee for some members, available information resources do not cater for major information needs, not able to share in case of regional branches, and resources not available to all.

Mwanzia (2014) suggested promotion of KLISC, improve infrastructure, fair treatment, independent secretariat for KLISC, separation of KLISC's accounts from that of Nairobi University, and effective communication.

\section{PROBLEM STATEMENT}

KLISC has done admirable activities to support research in Kenya. These activities incorporate collaborative acquisition of information resources, ICT training of information experts and the preparation of researchers to improve their abilities in retrieving information. Despite the activities and services that KLISC provide, its resources are yet to be appreciated by a majority of the users of the member institutions. Also, not all information providers and institutions of higher learning are members. Kenya has over 600 institutions but only 112 are KLISC members. the study therefore tried to identify the challenges that the KLISC members face that could be affecting utilization of the electronic resources and also discouraging other institutions from joining.

\section{RESEARCH AIM}

The study aimed at identifying the challenges that affect the utilization of KLISC's resources and services.

\section{RESEARCH METHOD}

The study used descriptive survey design. Descriptive survey is a method of collecting information by interviews or administering questionnaires to a sample of individuals. The design utilizes both elements of quantitative and qualitative research methodologies. The study population was drawn from member libraries of KLISC in Nairobi County and KLISC's executive committee. The targeted population was 2 UoN's Librarians (Director and acquisition librarian) 9 KLISC's executive members and 1342 post graduate students from UON's School of Business, totalling to 1353.

The librarians together with the KLISC's representatives were purposively selected while the post graduate students were selected using simple random sampling.

The study sample consisted of the library director and acquisition librarian of Jomo Kenyatta Memorial Library, 3 KLISC executive management committee (chairman, secretary and treasurer) and post graduate students from School of Business at UoN. The determination of the sample size was guided by a simplified formula for proportions, (Israel, 2003). The formula 
was used to get the sample size of the students as the library directors and KLISC's representatives were purposively selected.

$$
\begin{aligned}
& \mathrm{n}=\mathrm{N} \\
& \left(1+\mathrm{N} *(\mathrm{e})^{2}\right) \\
& \text { Where } \\
& \mathrm{n}=\text { Sample size } \\
& \mathrm{N}=\text { population size } \\
& \text { e=level of precision or sampling error } \\
& \text { 95\% Confidence level and Precision=.1 } \\
& =1342 /\left(1+1342(0.1)^{2}\right) \\
& =99.93=100
\end{aligned}
$$

Table 1. Sample Size. Source: (Researcher, 2018).

\begin{tabular}{lll}
\hline Respondents & Population size & Sample size \\
\hline JKML librarians & 2 & 2 \\
KLISC executive committee & 9 & 3 \\
UoN post graduate Students & 1342 & 100 \\
Total & $\mathbf{1 3 5 3}$ & $\mathbf{1 0 5}$ \\
\hline
\end{tabular}

\section{RESULTS}

The study's main objective was to identify the challenges that KLISC members were facing that affected the utilization of KLISC's resources and services. This would help to suggest solutions for the challenges that would maybe increase KLISC's membership.

The study posed a question to interrogate the challenges that the users, librarians and KLISC itself faced. 76 respondents translating to $84 \%$ of the total respondents were faced with slow internet connectivity, 57 respondents or $63 \%$ were information illiterate, 55 respondents or $61 \%$ lacked the searching skills, 43 respondents (48\%) had low awareness levels of the information resources, 21 respondents (23\%) experienced slow downloading speed, while 14 respondents or $16 \%$ found the databases' platforms to be user unfriendly. None complained of unreliable electricity supply probably because of the availability of an automatic generator.

Figure 1 below shows how the users responded. The respondents were allowed to select multiple choice. 


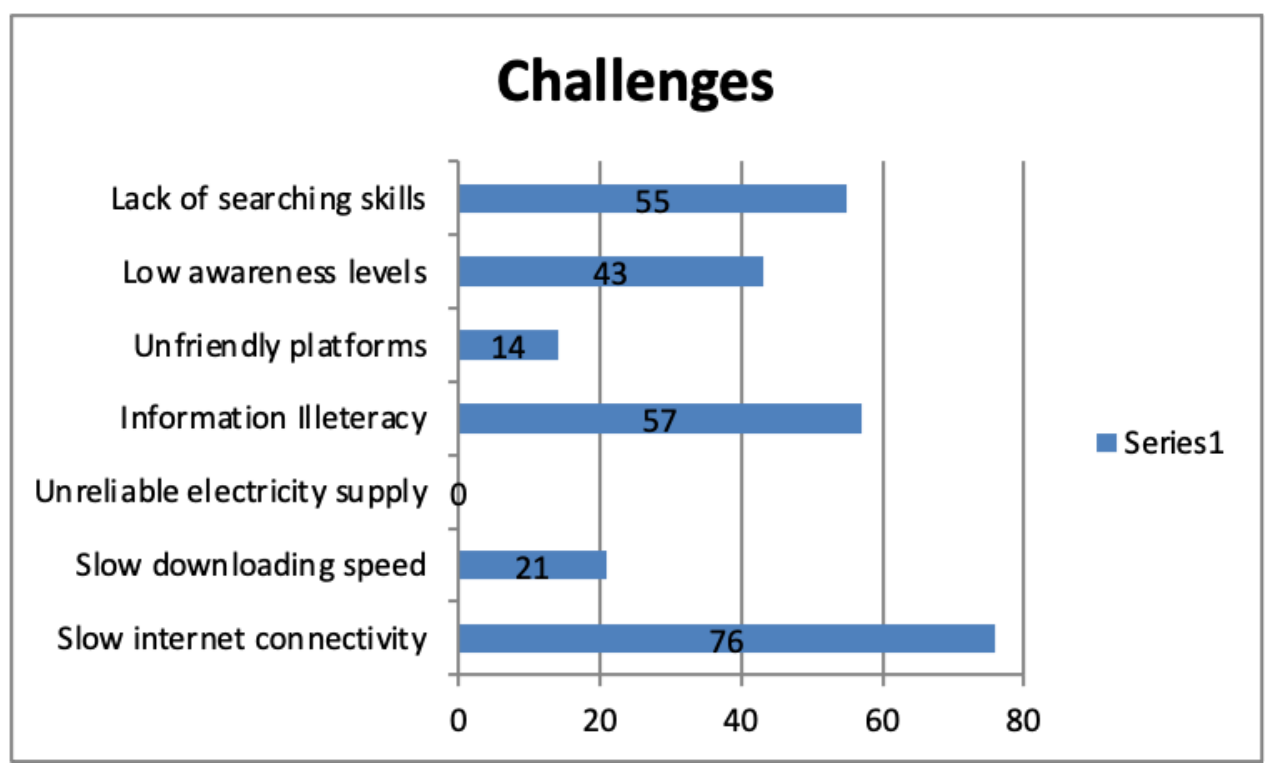

Figure 1. Challenges. Source: Field Data (2019).

The Librarians also added the following challenges: UoN's library director indicated that, "some of these databases have password requirements while other have long embargo periods for specific articles and books which limits their access. Major information needs are also not much catered for and therefore we have had to individually subscribe to other specialized databases." She also added the following challenges: restriction to full text by some publishers, poor ICT infrastructure, limited skills by staff, slow communication by the publishers especially in communicating changes and also setting up of administrator accounts. The acquisition librarian added that many institutions' management delay in releasing the annual KLISC subscription fee which affects all the members. An example given was that of EbscoHost which was inaccessible to all the KLISC members even those who had already remitted their annual subscription fees. The KLISC representatives were also asked about the challenges they face and they cited that the members did not communicate about their information needs in time and also delay in paying their annual subscription fees. One representative indicated that, "KLISC is facing financial problems courtesy of delay by members to submit their subscription fees which results to a delay in KLISC remitting the same to the publishers. At the time, EbscoHost is not accessible to all the KLISC members since KLISC has not paid. The financial problem has also made KLISC to be reluctant about marketing itself to the non-members since it is unable to manage the ones it has." Another representative added that, "our recent challenge is that of INASP (International Network for the Availability of Scientific Publications) pulling out its support." INASP had supported KLISC for 8 years and in 2017 its time expired. Though this was expected, it is a challenge as KLISC has to now stand on its own. One representative also added that they get overwhelmed since they have demanding positions at their places of work other than being KLISC's executive committee.

In support of the above results, Veenapani et al (2008) also reported information illiteracy and poor web availability as the main challenges. Thanuskodi (2012) in his study found out that 
user-unfriendly platforms and slow internet were the main challenges while Dzanda and Alemna (2011) reported that delayed release of funds from mother institutions and denied access to full text by some databases were the challenges. Kiilu et al (2011) and Mwanzia (2014) also reported staff's lack of ICT skills as a challenge.

\section{SUGGESTIONS TO THE CHALLENGES}

76 respondents suggested that a reliable service provider be sourced to improve on internet connectivity. 65 respondents suggested that internet bandwidth be increased so as to reduce downloading time. 57 respondents requested that more attention be focused on information literacy program while 55 respondents indicated that more training should be done on access and use of the KLISC's information resources. 43 respondents suggested persistent marketing of the KLISC's information resources so that more patrons become aware of them while 37 respondents requested of improvement of the ICT infrastructure. 14 respondents believed that if the databases' platforms were made user-friendly, this would solve their problems.

The UoN's library director indicated that, "improved ICT infrastructure will go along away in ensuring that these information resources are conveniently accessed and utilized by our patrons. This also entails more computers to cater for our large numbers of patrons, the university might not be able to acquire enough computers for all its patrons and therefore we request those patrons who are able to acquire laptops for themselves to do so. Those with Smart phones can also be able to access the resources". The director also made a plea to the management to adequately support the course especially when it comes to funding and budget allocation to the library. She also requested that KLISC should find a way of dealing with the institutions that delay in paying their annual subscription fees independently and in a way that does not affect all the members.

The KLISC management representatives' suggestions were that KLISC should be promoted and marketed more and that effective communication to be worked on. They also suggested that ICT infrastructures for the individual institutions be improved for effective availability of electronic resources. This is in line with Mwanzia's (2014) suggestions, that is, promotion of KLISC, improve infrastructure, fair treatment, and independent secretariat for KLISC, separation of KLISC's accounts from that of Nairobi University, and effective communication.

\section{CONCLUSION AND RECOMMENDATIONS}

The study concluded that KLISC members experienced the following challenges; slow internet connectivity, information illiteracy, lack of searching skills, low awareness levels, slow downloading speed, unfriendly platforms, password requirements for some databases, poor ICT infrastructure, poor ICT skills for both users and staff, delays in releasing of funds by the management, and slow communication from the publishers. KLISC itself faces the following challenges: members do not efficiently communicate about their information needs, lack of sponsorship since INASP pulled out, delay by KLISC's members to pay their annual subscription fee, and the management team is overwhelmed by work. 
The study therefore recommended the following:

- Institutions should invest more on ICT infrastructure to cater for the huge number of users in need of these information resources. This includes acquisition of more computers and also increased bandwidth for the institution to boost the internet speed.

- KLISC should come up with a way of ensuring relevancy such as availing highly specialized databases to cater for institutions dealing with specialized fields. Institutions should also take it upon them to look for relevant databases to their users as well as frequently forward their information needs to KLISC.

- KLISC should stand on its own as an institution and acquire its own offices and employ staff who will just be working for KLISC.

- KLISC should create a mini-consortium to cater for research institutions and also other specialized fields in different institutions in Kenya.

- The publisher should improve the interfaces of their databases to make them user friendly and easy to navigate.

- The publishers should also ensure fast communications with the institutions and if possible give administrator accounts as soon as an institution subscribes to their databases.

\section{References}

Chadwell, F. A. (2011). Assessing the value of academic library consortia. Journal of Library Administration, 51(7-8), 645-661. https://doi.org/10.1080/01930826.2011.601268

Chander, R., \& Gupta, A. (2015). Library consortia in India. Kowledge Librarian: An International Peer Reviewed Bilingual e-Journal of Library and Information Science, 2(3).

Fresnido, A. M. B., \& Yap, J. M. (2014). Academic library consortia in the Philippines. Library Management, 35(1/2), 15-36.

Galyani, G., \& Talawar, V. G. (2009). Library consortia in developing countries: an overview. Program, 43(1), 94-104. https://doi.org/10.1108/00330330910934138

Islam, M. A., \& Mezbah-ul-Islam, M. (2000). Concept, issues and importance of library consortium: Problems and prospects of university library consortium in Bangladesh. University of Dhaka: Bangladesh.

Israel, G. (2003). Determining sample size. Retrieved from https://www.tarleton.edu/academicassessment/documents/Samplesize.pdf

Kiilu, D., Gathoni, N., \& Kabugu, A. (2011). Monitoring and Evaluation of Electronic Resources in Academic and Research Institutions in Kenya. INASP/KLISC.

Posigha, B. E., Godfrey, V. Z., \& Seimode, F. D. (2015). The trend of academic libraries consortia in the north central and south east geo-political zones of Nigeria. Library Review, 64(4/5), 305-320. https://doi.org/10.1108/LR-07-2014-0084

Thanuskodi, S. (2012). Awareness and usage of UGC-Infonet Digital Library Consortium among faculty members of state universities in Tamil Nadu: A survey. International Journal of Information Science, 2(3), 13-18. https://doi.org/10.5923/j.ijis.20120203.02 
University of Nairobi. (2017). UON Profile | UNIVERSITY OF NAIROBI. Retrieved August 24, 2017, from University of Nairobi website: http://uonbi.ac.ke/about/profile Veenapani, S., Singh, K., \& Devi, R. (2008). Use of e-resources and UGC-Infonet Consortium by the teachers and research scholars in Manipur University. International CALIBER, 563.

\section{About the authors}

Naomy Mwaurah is the Assistant Librarian at Boma International Hospitality College.

Ben Wekalao Namande is a lecturer and the chairperson of the Research and Innovation Committee at Kisii University. He is also a part-time lecturer at Kenyatta University. 